'from the planet' would take two more decades and probably require a vaccine, to say nothing of the need for Africa's governments to take responsibility. 'Durable accomplishments would require Africans to take over... [This was] the world's biggest aid drive 2009-2010 ... What would happen when the world found another cause?... Could [Africa] finally begin climbing its own virtuous circle of development?' Control rather than eradication of mankind's oldest disease remains the goal even after this flat-out, foot-to-the-floor philanthro-capitalist effort.

Perry's book deserves a broad popular audience. He has carried off the uncommon feat of making, without mawkishness, a grim topic into a quietly inspiring and genuinely exciting story.

Martin Mulligan (C) 2012

Financial Times

http://dx.doi.org/10.1080/00358533.2012.736278

\title{
The Non-independent Territories of the Caribbean and Pacific: Continuity or Change?
}

Peter Clegg and David Killingray (Eds)

London, Institute of Commonwealth Studies, University of London, 2012, pp. 206, ISBN 978-0-9569546-0-2 (paperback)

Those observing the dazzling opening ceremony of the London 2012 Olympic Games may have noticed that not all athletes were marching proudly behind their national flag. There were at least two 'independent athletes' marching behind the Olympic five-circle flag: Philippe van Aanholt (sailing) and Reginald de Windt (judo). They are from the former country of the Netherlands Antilles, which was 'dissolved' on 10 October 2010; and so the Netherlands Antilles Olympic Committee had its membership in the International Olympic Committee (IOC) withdrawn. That would have left these two Olympic-standard athletes without a nation to compete for in London. And so, Philippe and Reginald were allowed to participate in the Games as independent athletes, even though they could have chosen to compete for Aruba or the Netherlands, as they both have Dutch nationality.

Some may be surprised: the IOC has 204 'countries' as members, whereas most counts of independent sovereign states today would come up with a tally of 194-196 (depending on whether one counts Taiwan and Kosovo). That is because some 'countries', as some autonomous territories are called, are not independent states: they include Aruba, which has been a separate country within the Kingdom of the Netherlands since 1986. They also include places such as Bermuda, Cayman, Puerto Rico, US Virgin Islands and the (British) Virgin Islands in the Caribbean; and American Samoa, Cook Islands and Guam in the Pacific: all are full members of the IOC.

Since 1968, when even tiny Nauru with a total population of 10,000 became a sovereign state, the conventional wisdom had it that small size was no plausible impediment to sovereignty. Thus it has been customary since then to consider subnational jurisdictions, mostly islands, as states-in-the-making; they were small, and perhaps that was why they were taking longer to become fully sovereign. But sovereign they would become: they were almost there. Their condition has been 
imaginatively described by Denicio Brison (a politician from Dutch Sint Maarten) as 'a colonial hangover that they do not know how to cure' (p. 76); or perhaps one that they may not wish to cure. So much is clear: although there are some rumblings of independence - with referendums slated to take place soon in Bougainville, New Caledonia and Scotland - there is hardly any appetite for a political status that would sunder once and for all a significant lifeline that connects these small jurisdictions to larger and prosperous metropolitan states that may have their own 'colonial hangover', and still feel some obligation to make up for their imperialist past. All the more so in a globalised and turbulent world, now reeling from a serious financial crisis where the free access to the labour markets of rich countries could be an 'ultimate prize' (p. 79): the key ticket for economic survival, social mobility and prosperity. In principle, it appears wise and shrewd to play a game that allows for a 'best of both worlds' scenario (p. 80): creaming off the security, welfare, finances and citizenship benefits of mainly four developed countries - the United Kingdom, France, the Netherlands and the United States - while enjoying significant degrees of local discretionary power and autonomy. John Connell has a fine term for this stance: 'an infinite pause' - one step away from independence; but that final step remaining purely academic; a 'hypothetical option' (p. 67) only.

The situation on the ground is, however, changing; and this is the context of this superb, handy and timely volume. Peter Clegg and David Killingray have come up with a primer discussing and dissecting the intricate situation pertaining in the enduring subnational (and mainly island) jurisdictions of these four countries - a welcome update on the slimmer but equally captivating text edited by the same Killingray, along with David Taylor in 2005, and then focusing mainly on the United Kingdom's Overseas Territories (UKOTs). Hence the apt subtitle to the book: continuity or change?

The answer is as complex as the number of cases being reviewed. The volume makes this amply clear: it is not possible to do justice to the intricate mainlandisland dynamics by addressing generic themes; even the status of these jurisdictions can be very different. In the case of the French examples, every single territory has its own unique status today (p. 95). Yet, there are powerful epistemological insights to be gleaned from deploying a comparative approach.

First of all, even in the last few years, the situation has changed in the home countries. The election of the Obama Administration in the US in 2008, and the initiative in favour of a Savings Tax Directive in the European Union since 2005, have ushered in a political climate that is not sympathetic to 'tax evasion'. Serious initiatives are in place to try and rein in the considerable amount of capital that is parked in 'offshore finance centres' - also called 'secrecy jurisdictions' (p. 130) especially at these current times when hugely indebted governments are starved of income, or, as in France with the election of François Hollande to the Presidency in 2012, have come to an abrupt realisation that all is not well with their public finances. Moreover, public opinion in the heartlands about former colonial peoples has hardened: almost all of Western Europe-France, Denmark and Norway are the exceptions-has elected right-leaning governments that embrace anti-immigrant coalition parties, or are very sensitive to the manner in which public opinion has assumed a more nationalist and proto-ethnic discourse that may caricature their overseas territories as Absurdistan (e.g. p. 70): nothing short of comic and stubbornly 
parasitic appendages. Regional and international obligations - on halting drug trafficking, rescinding corporal punishment and the death penalty, respecting homosexual rights, stamping out corruption, and ensuring good governance generally - mean that Amsterdam, London, Paris and Washington have been careful not to delegate, let alone devolve, any local powers to their smaller wards without ensuring some control or influence over financial management and, as a last resort, constitutional politics: the Turks \& Caicos Islands, a UKOT, had its constitution suspended in 2009 after evidence of 'systemic corruption' was unveiled; a new constitution has been drafted but will be implemented only after a series of milestones are met. The UK will not find itself again in a situation where it has all the responsibility but 'no executive authority' (p. 8). There has been a flurry of constitutional reform of late, to address such a lacuna.

The flip side to this is what is happening in the territories themselves: demands for more autonomy in the French Pacific have been met by renewed assertions of the indivisibility of the French nation. Secession from the clutches of Curaçao/ Netherlands Antilles (for Bonaire, Saba, St Eustatius and Sint Maarten) and Guadeloupe (for St Barthélemy and St Martin) means not only more direct relations with the metropole, but also more fiscal constraint. Less constraint would mean less financial support (p. 100). The UK Offshore Finance Centres (OFCs) (especially Bermuda and Cayman), along with the Channel Islands and the Isle of Man, are concerned with how to ride the current storm over their serving as tax havens. Ironically, a worsening of this crisis would strengthen the hand of those who would make the case for outright independence. Meanwhile, natural resource availability in jurisdictions such as the Falklands (with proven oil and gas seabed deposits, plus a vociferous and sabre-rattling Argentina) and Greenland (coveted by China for its rare earth metals, plus straddling newly accessible Arctic sea-lanes) means that their local governments can negotiate from positions of strength with their central governments.

For those jurisdictions offering 'financial services', it may be time to look for a Plan B. Yet, this is very difficult to execute in practice. Not just because of 'cognitive lock-in' (p. 134): a paradigmatic paralysis that prevents policymakers in these territories from realising that the proverbial writing is on the wall. Not just because of 'Dutch Disease', whereby the whole economy gears up to service one dominant sector, and fails to support anything else. This absence of proactive policy is also a function of small state politics: many of these jurisdictions are trend takers rather than trend setters - they often have no choice but to fashion instruments that respond to, rather than tweak, market forces. Theirs is a predicament of boom and bust; and it is by definition ever so hard to see what will take up the slack when the current wave of prosperity reaches - sooner or later-its inevitable demise.

Clearly, the world map will not be tidied up any time soon. This collection, with contributions from policymakers, academics and former government advisors, is a strong reminder of the resourcefulness of jurisdiction, and how political status is directly linked to economic development. 